\title{
Applications of Polymeric and Lipid Nanoparticles in Ophthalmic Pharmaceutical Formulations: Present and Future Considerations
}

\author{
Hugo Almeida ${ }^{a *}$, Maria Helena Amaral ${ }^{\mathrm{a}}$, Paulo Lobão ${ }^{\mathrm{a}}$, Ana C. Silva ${ }^{\mathrm{a}, \mathrm{b}}$, José Manuel Sousa Lobo \\ ${ }^{a}$ Research Centre for Pharmaceutical Sciences, Laboratory of Pharmaceutical Technology, Drug Sciences Department, \\ Faculty of Pharmacy, University of Porto, Portugal. \\ ${ }^{\mathrm{b}}$ Faculty of Health Sciences, Fernando Pessoa University, Porto, Portugal.
}

Received, April 16, 2014; revised, June 4, 2014; accepted, July 11, 2014, Published, July 13, 2014.

\begin{abstract}
The unique properties and characteristics of ocular tissues and the whole set of defence mechanisms of the ocular globe make the instillation of ocular drugs into a difficult task with a low rate of therapeutic response. One of the challenges for the new generation of ophthalmic pharmaceutical formulations is to increase the bioavailability of drugs administered by the ocular route and, therefore, their therapeutic efficacy. This can be achieved with the use of some strategies that provide an increase in the formulation pre-corneal residence time, mucoadhesion and penetration across the eye tissues. Colloidal carrier systems have been very successfully used for the selective and targeted delivery of drugs for several routes of administration. In this context, nanoparticles prepared with specific polymers or lipids and coated, dispersed or suspended in polymer solutions with mucoadhesion properties or in situ gelling properties will be an excellent strategy that deserves attention and further research. In this review, the characteristics and main properties of polymeric and lipid nanoparticles are discussed and examples and advantages of the application of these colloidal carrier systems for the ophthalmic administration of drugs are presented. The future directions of the research required in this specific field are also presented.
\end{abstract}

This article is open to POST-PUBLICATION REVIEW. Registered readers (see "For Readers") may comment by clicking on ABSTRACT on the issue's contents page.

\section{INTRODUCTION}

The eye is a complex organ composed of several different structures and layers, with specific physiological roles (Figure 1). One of the most important functions of these structures is to protect the ocular globe against external aggressions. Accordingly, when a foreign body is applied to the eye, the natural reaction is to eliminate it immediately. Therefore, the topical ocular instillation of drugs is challenging, since the compounds must remain in the eye for enough time to be absorbed (1-6). In fact, there are several reasons for the low therapeutic efficacy of traditional ophthalmic dosage forms, such as $(1,2,7-17)$ : lacrimation and blinking, tear dynamics, drainage by gravity, nasolacrimal drainage (the residence volume of the tear film is 7-10 $\mu \mathrm{l}$, while the human cul-de-sac may contain about $30 \mu \mathrm{l}$ volume. The excess is removed through the nasolacrimal drainage system), the absence of both controlled release and bioadhesive properties, and the presence of several physiological barriers to the eye (e.g. cornea, conjunctiva, sclera).

In order to improve the therapeutic efficacy of ophthalmic pharmaceutical formulations, by means of increasing the pre-corneal residence time and the corneal penetration of the applied drugs, different approaches have been used, such as hydrogels, in situ gelling systems, microparticles and colloidal carriers (e.g. micelles, drug nanosuspensions, nanoemulsions, liposomes, and lipid and polymeric nanoparticles) $(6,7,11,14,15,18-24)$. Among these, the use of colloidal carrier systems, particularly lipid and polymeric nanoparticles, has been showing promising results for the topical administration of ophthalmic drugs (25). Therefore, according to the aim of this review, we will focus on these two carrier systems. The use of drug-loaded nanoparticles in ophthalmic formulations presents several advantages, namely $(2,5,6,25,26)$ : biocompatibility and biodegradability; high drug loading and encapsulation efficiency; drug

Corresponding Author: Hugo Almeida, Research Centre for Pharmaceutical Sciences, Laboratory of Pharmaceutical Technology, Drug Sciences Department, Faculty of Pharmacy, University of Porto, Rua Jorge Viterbo Ferreira, $\mathrm{N}^{\circ}$ 228, 4050-313, Porto, Portugal; Email: hperas5@hotmail.com 
protection from degradations; eye drug target; improvement of drug penetration through the eye, enhancing its bioavailability; increase of longterm stability of formulations.

In order to facilitate their ocular application, nanoparticles should be administered in a vehicle that allows for application by means of eyedrops $(3,15,28,29)$. Typical colloidal carriers are dispersions with low viscosity, which leads to a low drug ocular bioavailability, due to the rapid pre-corneal mechanism of elimination $(30,31)$. To avoid this drawback, these systems could be incorporated in semi-solid systems, increasing their viscosity and long-term stability (30). Nanoparticles coated, dissolved or suspended in mucoadhesive polymers or in situ gelling (i.e. stimuli-responsive) polymers increase pre-corneal residence time and promote drug absorption $(5,6,11,16,29,32-40)$.

Nonetheless, the use of mucoadhesive polymers or stimuli-responsive polymers in ophthalmic formulations requires an interaction between the formulation and the ocular tissues. This could be obtained by the establishment of polymer linkages with the mucin present in the tear fluid, through hydrogen bonding, or electrostatic, covalent and hydrophobic interactions $(29,41)$. These in situ gelling systems are composed of specific polymers, which undergo a sol-gel transition in the presence of specific physicochemical characteristics of the eye surface (e.g. temperature, $\mathrm{pH}$ and electrolytes of the tear fluid), increasing the viscosity and the residence time of the formulation in the ocular globe. Therefore, the polymers used in such formulations should be compatible with the physiological characteristics of the different eye tissues, in order to allow the drugs to penetrate through the eye barriers and reach the intraocular tissues (3-6, 16,25,27,33-39,42-46).

\section{ANATOMY AND PHYSIOLOGY OF THE OCULAR SYSTEM}

The human eye is composed of two anatomical regions: (i) the anterior segment, which comprises the cornea and conjunctiva; (ii) the posterior segment, which comprises the retina. Figure 1 illustrates the principal structures of the ocular globe.

The cornea is the clear transparent surface of the outer eye, with about $0.5-1 \mathrm{~mm}$ of thickness (47). This is a non-vascularized structure, composed of five layers, namely the epithelium (a major hydrophilic barrier), Bowman's membrane, the stroma (a major lipophilic barrier), Descemet's membrane and the endothelium (a minor lipophilic barrier) (47). Therefore, this structure acts as a barrier and exhibits high resistance to passive diffusion of drugs (27). On the other hand, the conjunctiva is a thin vascularized mucus membrane with a clear transparent surface, which covers the anterior part of the sclera up to the cornea $(15,16,27,47)$. In this structure the absorption of some drugs also occurs $(16,48)$. The goblet cells of the conjunctiva secrete approximately 2-3 $\mu$ l of mucus per day, which covers the eye surface, and has the function of hydration, cleaning and lubrication and serves as a defence against pathogens (15).

\section{Structure of the Eyeball}

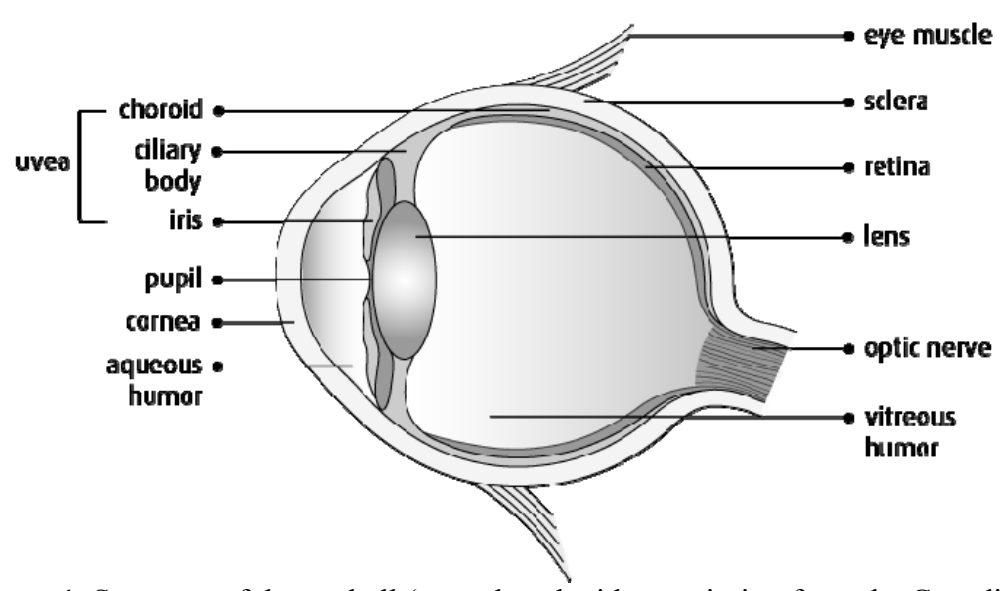

Figure 1. Structure of the eyeball (reproduced with permission from the Canadian Cancer Society). 
The sclera is an opaque fibrous protective layer, slightly elastic, with a similar composition to the cornea, that maintains intraocular pressure and serves as the attachment site for the extraocular muscles $(47,49,50)$.

The eye surface is covered by a pre-corneal tear film, secreted by the conjunctival and lacrimal glands (47). This fluid is composed of three layers, namely the superficial lipid layer, the middle aqueous layer and the deep mucous layer $(7,15)$. The superficial lipid layer is secreted by the Meibomian glands (which produce esters, triacylglycerols, free sterols, sterol esters and free fatty acids) and by the conjunctival goblet cells (which produce mucin) (51). This layer prevents the evaporation of the aqueous layer, maintains the surface tension of the tear film and lubricates the corneal and the conjunctival surfaces (52). The aqueous portion contains a salt solution that is secreted by the main and accessory lacrimal glands and represents $90 \%$ of the tear film (51). This layer contains inorganic salts, glucose and urea, as well as biopolymers, proteins and glycoproteins (53).

\section{COLLOIDAL CARRIERS - GENERAL CONSIDERATIONS}

One of the best strategies for improving the bioavailability of ocular drugs is to develop delivery systems that act as drug reservoirs, prolonging the residence time, controlling the release and, therefore, decreasing the frequency of administration (4). Accordingly, several studies regarding the development of new ophthalmic drug delivery systems have been conducted. These colloidal carriers present several advantages for ophthalmic administration, including:

- Small particle size, with adhesive properties $(2,25,29,54)$;

- Improvement of the bioavailability of poorly water-soluble drugs $(7,25,26,29,30,37,55,56)$;

- Protection of sensitive drug molecules (especially against enzyme inactivation) $(4,25,26,43)$;

- Biodegradable, biocompatible and non-irritant features with corneal epithelial cells $(25,26,29,43,57)$;

- Improvement of drug pre-ocular retention, promoting absorption $(7,25,29)$;

- Targeted and controlled release characteristics, reducing or preventing side effects, being ideal for long-term treatments $(25,29,58-61)$.
As previously mentioned, among colloidal carriers, lipid and polymeric nanoparticles are the most promising for ophthalmic drug delivery and their use could revolutionize the therapy of many eye diseases $(14,25,29)$. Despite not being a consensual concept, nanoparticle systems are those containing particles with sizes smaller than $1000 \mathrm{~nm}$. Nonetheless, the use of drug-loaded nanoparticles with an average diameter ranging from 50 to $400 \mathrm{~nm}$ constitutes a versatile ocular delivery system, which has the ability to overcome physiological barriers and to direct the drug to specific cells or intracellular compartments, either by passive or ligandmediated targeting mechanisms $(4,7,14,15,25)$. Moreover, smaller particles are better tolerated by patients than large ones, because the former are more able to penetrate across the corneal barrier $(4,15,29)$. However, the tissue accumulation and aggregation of nanoparticles in the eye tissues can cause some problems that affect the normal functioning of the eye (4-6). Colloidal drug delivery systems are absorbed by the corneal epithelial cells, which function as a reservoir to release the drug slowly to the surrounding tissue. These prevent tear washout providing a sustained release of the ocular drugs $(25,41)$. For ocular instillation, nanoparticulate carrier systems are required to have a low average particle size, with the lowest polydispersity index possible in order to promote the corneal uptake, promoting mucoadhesion and reaching the inner tissues of the eye $(55,62)$.

\section{POLYMERIC NANOPARTICLES}

Biodegradable polymeric nanoparticle systems, ranging in size from 10 to $1000 \mathrm{~nm}$, are the most popular systems in ocular carrier therapy $(2,25)$. These systems can be composed of various polymers in which the drug is dissolved, entrapped or encapsulated. Drugs can either be integrated in the matrix or attached to the surface. Polymeric nanoparticles can be divided into two subtypes, namely (i) nanospheres, where the drug is uniformly dispersed in the matrix or adsorbed in the surface of the nanoparticle; (ii) nanocapsules, which are small capsules with a central cavity where the drug is dissolved or dispersed and is surrounded by a polymeric membrane $(2,4,25)$.

Polymeric nanoparticles offer several advantages for ophthalmic drug delivery, namely $(25,29)$ : biodegradability, non-toxicity, biocompatibility, mucoadhesiveness (bioadhesion and interaction with the glycoproteins of the cornea and conjunctiva), ease and low cost of 
production, and the possibility of obtaining stable systems after lyophilization and reconstitution, which increases the long-term stability of the systems. These nanosized particles enhance the bioavailability of ophthalmic drugs, because of their ability to overcome physiological barriers, increasing the amount of drug in the site of therapeutic action (by passive or ligand-mediated targeting mechanisms), thus decreasing the dose required and the side effects, without blurring the vision (29). However, some authors describe some potential disadvantages of these types of nanoparticles, related to some toxicity concerns, which are the fact that the degradation of the polymers might cause systemic toxic effects and the required use of organic solvents for production may originate some residual toxicity in the final formulations. This could explain why currently only a few polymeric nanoparticle-based systems are used in clinics (63-65).

Depending on the characteristics and properties of the polymer(s) and the drug used, these types of nanoparticles is manufactured through simple techniques, namely precipitation/coacervation, modified coacervation, ionotropic gelation, spontaneous emulsification/solvent diffusion and quasi emulsion solvent diffusion (QESD) (29).

Among the most important features required for ophthalmic nanoparticles are the ability for retention in the ocular tissues, a nanosize diameter and the use of polymers with mucoadhesive properties (e.g. polyacrylates, polyalkylcyanoacrylates, poly(lactide-coglycolide), poly(lactide), poly $\varepsilon$-caprolactone, albumin, dextran gelatin, alginate, collagen, hyaluronic acid (HA) and chitosan (CS)) (2,29,41,45,66-70). Mucoadhesiveness of biodegradable polymers minimizes the drainage from the eye, by interacting with the mucin present in the ocular surface throughout hydrogen bonding, or electrostatic, covalent and hydrophobic interactions, which increase the precorneal residence time and, therefore, the bioavailability of the drug $(29,41)$. Without these properties, nanoparticles are eliminated from the pre-corneal site as fast as aqueous solutions $(2,29,41)$.

As previously mentioned, different authors have developed polymeric nanoparticle systems with modified surface properties by coating with different mucoadhesive polymers in order to enhance the interactions with the mucin of the ocular mucosa. Examples of these are: PEG (Polyoxyethylene glycols), poloxamers, poloxamines, HA, CS, poly(acrylic acid), sodium alginate, and others $(23,29,41,45,55,68-70)$.

Chitosan (CS) is a mucoadhesive, $\mathrm{pH}-$ responsive polymer (it is a polycation that undergoes sol-gel transition at $\mathrm{pH}$ 7.4) with pseudoplastic and viscoelastic behaviour, which has the capacity to establish hydrogen bonds between their positively charged amino groups and the negatively charged sialic acid residues of mucin, prolonging the corneal residence time of drugs $(3,11,27,29,34,42-46)$. De campos et al. (2001) (71) prepared CS nanoparticles formulated with cyclosporine A (CyA) and the in vitro studies performed with these nanoparticles showed a fast drug release during the first hour followed by a more gradual release over a 24 hours period, whereas in vivo studies performed in rabbits showed therapeutic concentrations of CyA over 48 hours. Later, De Campos et al. (2004) (72) demonstrated that CS nanoparticles are promising vehicles for ocular drug delivery and were well tolerated. The amounts of this colloidal system in the cornea and conjunctiva were significantly higher than the control CS solution and these nanoparticles have the advantage of being able to penetrate the cornea and the conjunctival epithelia.

Giannavola et al. (2003) (73) prepared acyclovir-loaded poly- $d, l$-lactic acid (PLA) nanospheres and studied the differences in terms of bioavailability and therapeutic efficacy between nanoparticles uncoated or coated with PEG. In fact, both formulations showed a sustained release of acyclovir and were well tolerated, but nanoparticles coated with PEG showed greater efficacy than the uncoated PLA nanoparticles.

The research team of Kao et al. (2006) (74) developed pilocarpine-loaded CS/Carbopol nanoparticles. All properties including in vitro and in vivo tests were compared in different ophthalmic formulations of pilocarpine, namely solutions, gels and liposomes. CS/Carbopol nanoparticles had the advantage of being biocompatible, biodegradable and mucoadhesive and showed a sustained release profile of pilocarpine when compared with the other preparations.

With the same purpose, Yuan et al. (2008) (44) developed polymeric nanoparticles prepared with CS and PLA nanoparticles loaded with rapamycin. This type of nanoparticle has provided a good retention and a sustained release of rapamycin on the rabbit cornea. Motwani et al. (2008) (43) formulated gatifloxacin in chitosansodium alginate nanoparticles. Sodium alginates 
are used in ophthalmic formulations because they present many advantages, namely biodegradability, biocompatibility and mucoadhesive properties and suffer sol-gel transition in the presence of di- and trivalent metal ions present in tear fluid $(4,43,75)$. The results showed that the chitosan-sodium alginate nanoparticles have mucoadhesive properties and that there is a sustained ocular delivery of gatifloxacin over 24 hours, having verified, however, a rapid release during the first hour (43).

In another study, gatifloxacin/prednisoloneloaded nanoparticles of Eudragit RS 100 and RL 100 coated with mucoadhesive polymer hyaluronic acid (HA) were prepared. The results of this study showed a prolonged drug release over more than 6 hours, whereas the duration of the effect of the commercial eye drops lasted approximately 2 hours. The authors of this study concluded that this kind of strategy increased the pre-corneal residence time and improved the drug penetration across the cornea $(4,76)$.

Mahmoud et al. (2011) (45) wanted to combine the advantages of CS with the advantages of cyclodextrins (polyanionic polymers and solubilizing agents of poorly watersoluble drugs). These authors prepared chitosan/sulfobutylether- $\beta$-cyclodextrin

nanoparticles loaded with econazole nitrate and in vivo studies performed in rabbits showed that such nanoparticles provided a sustained release of econazole nitrate and, therefore, an antifungal effect for a longer time than via the administration of a solution of the same drug.

In order to exponentially increase the bioavailability of polymeric nanoparticles, Nagarwal et al. (2012) (70) developed sodium alginate-chitosan nanoparticles loaded with 5Fluorouracil (5-FU) coated with CS. In this study, coating with CS caused an increase in viscosity and mucoadhesiveness compared with uncoated nanoparticles. The in vivo study of rabbits' eyes showed an increase in bioavailability of 5-FU in the aqueous humor of the eye and, therefore, an increase in therapeutic efficacy.

Bhatta et al. (2012) (77) prepared lecithin/chitosan mucoadhesive nanoparticles with natamycin. In vitro studies showed a biphasic drug release profile with an initial burst followed by a very slow drug release. On the other hand, in vivo studies performed in rabbits showed excellent mucoadhesion properties that prolong the ocular residence. In fact, the ocular residence time was increased up to 1.47 -fold and clearance was decreased up to 7.4-fold when compared to the marketed suspension containing the same drug (77).

Gupta et al. (2010 and 2011) $(66,67)$ reported two studies concerning the preparation of poly(lactic-co-glycolic acid) (PLGA) nanoparticles for topical administration of ophthalmic drugs, namely sparfloxacin and levofloxacin. In both studies, due to the small size of the nanoparticles, there was a high retention of the formulations in the ocular surface and a decreased elimination when compared with traditional formulations available on the market. The formulations developed provided a sustained ocular drug delivery and demonstrated good ocular tolerance $(66,67)$.

Gupta et al. (2013) (39) also developed polymeric nanoparticles of PLGA with sparfloxacin dispersed in a CS gel. These researchers called the combination of polymeric nanoparticles and in situ gelling systems "nanoparticle laden in situ gel". The purpose of this study was to combine the small size of the nanoparticles of PLGA with the mucoadhesiveness, penetration enhancer and $\mathrm{pH}-$ responsive characteristics of the CS gel. The results of this combination show that the "nanoparticle laden in situ gel" was retained for a long time in the eye, promoting a sustained release when compared to the nanosuspension and the in situ gel without nanoparticles (38). In another study, Gupta et al. (2013) (38) prepared polymeric nanoparticles of PLGA with levofloxacin dispersed in a CS gel. The results were identical to the study previously described, which demonstrates that the combination of these two strategies exponentially increased the bioavailability of ophthalmic drugs.

\section{LIPID NANOPARTICLES}

Lipid nanoparticle systems were developed from oil-in-water nanoemulsions, by replacing the liquid lipid of the former by a lipid that is solid at body and, obviously, normal room temperatures. Thereby, these systems consist of aqueous dispersions of particles with sizes ranging from 150 to $300 \mathrm{~nm}$, although higher and smaller sizes may be found $(58,78)$.

So far, when compared to other colloidal systems (e.g. liposomes and polymeric nanoparticles), lipid nanoparticles have been described as superior carriers. This contributes to their advantages for use as drug delivery systems, such as $(22,79,80)$ : low or absence of in vivo toxicity, related to the use of generally recognized as safe (GRAS) substances; protection of the drug molecules from degradations; good long-term 
stability; controlled drug release effect; specific drug targeting, improving bioavailability; economic production techniques, which do not require the use of organic solvents and ease the transfer to an industrial scale.

There are two types of lipid nanoparticle systems: the solid lipid nanoparticles (SLNs) and the nanostructured lipid carriers (NLCs). The former were first created and the latter emerged to circumvent the drawbacks pointed out of the SLNs, such as limited drug-loading capacity and drug expulsion during storage. The NLCs are also composed of a solid lipid matrix, which has blended a liquid lipid (usually up to $30 \%$ ) that confers a higher capacity for drug encapsulation. Therefore, the mixture of solid with spatially incompatible liquid lipids originate a structure with more imperfect crystal lattices, which can accommodate greater amounts of molecules, increasing drug loading and preventing storage expulsion (58).

As previously mentioned, SLNs and NLCs present several advantages for topical administration of ophthalmic drugs, such as $(3,14,15,25,26,29,40,41,58,81-87)$ : the ability to entrap lipophilic drugs, which extend their residence time and slow drainage, when compared to the conventional ophthalmic formulations; protection of the drugs from eye enzymatic degradation; adhesion to the ocular surface and interaction with the epithelium, depending on the nanoparticles size, shape and surface charge; lipid components might interact with the lipid layer of the tear film, enhancing the transcorneal drug delivery and prolonging the pre-corneal retention in the conjunctiva sac, which increases the ocular bioavailability of drugs.

The surface composition of the colloidal system may affect its affinity with the ocular mucosa. For example, a positive surface charge was found to have a beneficial effect in extending the residence time of an emulsion droplet on the epithelial layer of the cornea (41). Therefore, to increase the residence time of nanoparticles, they should be coated with cationic polymers to form positively charged systems, which promote the electrostatic interactions with the anionic surface of the cornea (15). In fact, the preparation of lipid nanoparticles with cationic lipids and/or surfactants promotes the electrostatic interaction of these formulations with the anionic eye tissues (25).

Lipid nanoparticles can be successfully produced by different methods, such as hot high- pressure homogenization (HPH), microemulsion, ultrasound and the techniques commonly used to prepare polymeric nanoparticles (e.g. solvent emulsification-evaporation, solvent displacement, emulsification-diffusion, phase inversion-based, ultrasonic solvent emulsification) (79,88). Nonetheless, the different characteristics and properties of the lipid nanoparticles (e.g. shape, structure and size) can be dramatically changed by the critical aspects of the production method used (e.g. temperature, pressure, number of cycles, duration). However, among these, the hot $\mathrm{HPH}$ remains the most efficient technique $(22,89)$. Suitable surfactants (lipids (e.g., lecithin, pure phospholipids), bile salts (e.g., sodium taurocholate) and biocompatible non-ionic molecules (e.g., ethylene oxide/propylene oxide copolymers, sorbitan esters, fatty acid ethoxylates) are essential for obtaining physicochemically and thermodynamically stable SLN and NLC systems. These surfactants form a film or layer that surrounds the solid lipid matrix in aqueous media and may influence its degradation rate. In fact, the nature of the lipid matrix, the composition and amount of surfactant(s) and the HPH process parameters influence the release kinetics of the ophthalmic drugs. Furthermore, the small particle size and the surface properties (surface irregularities are fundamental to the adhesion, because they increase the contact area due to the occurrence of van der Waals' interactions) are characteristics that increase the bioavailability of drug-loaded SLN/NLC in ophthalmic formulations $(2,25,26,90,91)$.

Cytotoxicity studies of SLNs and NLCs performed in various cell lines showed that these systems are well tolerated and non-irritant to the eye tissues (92). The critical point to the cytotoxicity of the NLCs seems to be the nature of the surfactants used in the preparation and, therefore, the non-ionic ones should be selected, as they cause lower toxicity and irritation to the eye tissues $(25,93)$. On the other hand, nanoparticles have the ability to provide and maintain the drug in a non-ionized form in front of the pre-corneal film and conjunctiva epithelium, facilitating transport through different ocular barriers and reaching more easily the intraocular tissues (4). Table 1 reports some recent results obtained for drug-loaded SLNs and NLCs in ophthalmic pharmaceutical formulations. 
Table 1. Examples of the use of drug-loaded SLNs and NLCs in ophthalmic pharmaceutical formulations.

\begin{tabular}{|c|c|c|}
\hline Pharmaceutical Formulations & Results & References \\
\hline $\begin{array}{l}\text { SLN as carriers for topical } \\
\text { ocular delivery of tobramycin }\end{array}$ & $\begin{array}{l}\text { - The in vivo study performed in rabbits evidenced that six hours } \\
\text { after instillation the tobramycin bioavailability in the aqueous } \\
\text { humour was significantly higher when compared with the } \\
\text { conventional formulations. } \\
\text { - The results of this study showed that the use of SLN enhanced } \\
\text { the retention time of the ophthalmic formulation on the ocular } \\
\text { surface. } \\
\text { - Diclofenac sodium SLN was prepared with a novel lipid matrix } \\
\text { consisting of } 30 \%(\mathrm{w} / \mathrm{w}) \text { of phospholipids (Phospholipon } 90 \mathrm{G}^{\circledR} \text { ) } \\
\text { in goat fat. }\end{array}$ & (94) \\
\hline $\begin{array}{l}\text { Diclofenac sodium } \\
\text { encapsulated in SLN }\end{array}$ & $\begin{array}{l}\text { - The results of this study showed an increase of encapsulation } \\
\text { efficiency in comparison to traditional SLN, a sustained release } \\
\text { of diclofenac sodium and a high permeation through the bio- } \\
\text { engineered human cornea (produced from immortalized human } \\
\text { corneal endothelial cells (HENC), stromal fibroblasts and } \\
\text { epithelial cells CEPI } 17 \text { CL 4). }\end{array}$ & $(95)$ \\
\hline & $\begin{array}{l}\text { - Cyclosporine A (CsA) loaded SLN was prepared by the high } \\
\text { shear homogenization and the ultrasound method using } \\
\text { Compritol }^{\circledR} 888 \text { ATO, Poloxamer } 188 \text { and Tween }{ }^{\circledR} 80 \text {. }\end{array}$ & \\
\hline $\begin{array}{l}\text { Cyclosporine A (CsA) loaded } \\
\text { SLN }\end{array}$ & $\begin{array}{l}\text { - The use of these two surfactants (Poloxamer } 188 \text { and Tween } \\
\text { 80) allowed the improvement of the formulation stability. } \\
\text { - Corneal cytotoxicity and cellular uptake tests performed in } \\
\text { rabbit's corneal epithelial cell lines (RCE) proved that this type of } \\
\text { nanoparticles were harmless and improve the penetration } \\
\text { properties across the corneal cells. } \\
\text { - Ibuprofen NLC were prepared by ultrasound method. } \\
\text { - Gelucire } 44 / 14 \text { (solid lipid material) and Transcutol P } \\
\text { (permeability enhancer) could enhance the corneal permeability } \\
\text { and the corresponding apparent permeability coefficients ( } \mathrm{P}_{\text {app }} \text { ) } \\
\text { were } 1.28 \text { and } 1.36 \text { times more than that of the control } \\
\text { formulation. }\end{array}$ & (57) \\
\hline Ibuprofen formulated in NLC & $\begin{array}{l}\text { - Optimized formulation of Ibuprofen loaded NLC proved to } \\
\text { have a bioavailability } 3.99 \text { times higher than the conventional } \\
\text { Ibuprofen eye drops. }\end{array}$ & \\
\hline
\end{tabular}


- NLC loaded cyclosporine A (CyA) was prepared by meltemulsification method.

- A mucoadhesive formulation was obtained by incubating the NLC dispersion with Cys-PEG-SA (thiolated non-ionic surfactant).

Cyclosporine A (CyA) NLC - In vivo studies performed in rabbits demonstrated that the coated with thiolated PEG encapsulated CyA was found to remain on the ocular surface in stearate the cul-de-sac up to $6 \mathrm{~h}$, both pre-corneal retention time and concentration were dramatically increased, compared with the NLC without thiomer modification.

- A flurbiprofen-loaded NLC formulation composed of stearic acid (SA) and castor oil (CO) and stabilized by Tween ${ }^{\circledR} 80$ (nonionic surfactant) in aqueous dispersion was produced by ultrasound method.

Flurbiprofen (FP) loaded - The optimized formulation showed to have nanoparticles with a ultrasound-engineered NLC mean diameter of $288 \mathrm{~nm}$, a polydispersity index (PI) of 0.245 and a zeta potential of $-29 \mathrm{mV}$.

- The flurbiprofen-loade NLC proved to be physico-chemically stable and did not show toxicity to the ocular tissues.

- A NLC loaded cyclosporine A (CyA) formulation was prepared by melt-emulsification method.

- Amucoadhesive NLC was obtained by incubating NLC nanoemulsion with Cys-PEG-SA and PEG-SA, respectively.

Thiolated NLC as a potential ocular drug delivery system for CyA

Optimization and

physicochemical

characterization of a

triamcinolone

acetonide-loaded NLC
- The in vitro CyA release from Cys-NLC was slower than that of non-thiolated NLC, due to the cross-linking of thiomers on the surface of nanocarriers.

- Thiolated NLC could deliver high level of CyA into intraocular tissues due to its bioadhesive property and sustained release characteristics.

- A triamcinolone acetonide-loade NLC was produced by high pressure homogenization, using Precirol ${ }^{\circledR}$ ATO5 and Squalene as solid and liquid lipids, respectively, and Lutrol ${ }^{\mathbb{R}} \mathrm{F} 68$ as surfactant.

- An optimized NLC formulation was prepared, with particles of (60) a mean diameter $<200 \mathrm{~nm}$, a negatively charged surface and high entrapment efficiency ( 95\%).

- The NLC formulation did not show toxicity and proved to be a promising alternative for delivery and controlled release of 
triamcinolone acetonide.

- Methazolamide SLN was prepared by a modified emulsionsolvent evaporation method.

Methazolamide (antiglaucoma - Results showed that this strategy improved the residence time drug) encapsulated in SLN and promoted the sustained release of the ocular drug, prolonging the therapeutic effect.

- Baicalin SLN was prepared by emulsification/ultrasonication method.

Baicalin formulated in SLN

- In vitro and pharmacokinetic studies showed that the SLN formulation promoted the prolonged release of baicalin and greatly increased the concentration of this drug in the ocular tissues when compared with the conventional eye drops.

- A flurbiprofen-loaded NLC formulation was prepared by meltemulsification and ultrasonication technique and then coated with COS (chitosan oligosaccharides).

Flurbiprofen NLC coated with - The clearance of the formulations was significantly delayed in chitosan (CS) oligosaccharides the presence of COS, comparing with non-coated ones.

- An enhanced transcorneal penetration was achieved by using the flurbiprofen NLC coated with COS.

\section{DEVELOPMENT OF OPHTHALMIC FORMULATIONS USING A COMBINATION OF NANOPARTICLES AND IN SITU GELLING POLYMERS}

\section{Future Directions}

Due to the low therapeutic response and efficacy of the traditional ophthalmic formulations, there are different strategies for improving the residence time and the corneal penetration of ocular drugs $(3,4,16,17)$. Nonetheless, in this review, we focus only on the most promising strategy that can enhance the ocular drug bioavailability, which is the use of nanocarriers, such as polymeric and lipid nanoparticles (SLNs and NLCs).

As can be seen in the previously mentioned studies, the use of this approach allows for an increased bioavailability and therapeutic efficacy of ophthalmic drugs, by prolonging the contact time between the pharmaceutical formulation and the corneal/conjunctival epithelium, enhances the permeability of ocular tissues to drugs, provides a specific drug targeting, promotes the sustained release of the ocular drugs, prolonging their therapeutic effect over several hours as opposed to traditional, commercially available ophthalmic formulations, reduces or prevents side effects, decreases the frequency of administration and increases the patient's adherence to therapy $(4,7,25,29,55,58-61)$.

In order to improve the results obtained with the nanoparticle-based formulations, one can proceed to the coating of these nanocarriers with specific substances, namely mucoadhesive polymers or stimuli-responsive polymers, which may cause a greater increase in the pre-corneal residence time and the corneal penetration of ophthalmic drugs. The use of specific polymers, i.e., positive-charged polymers (mucoadhesive polymers), for nanoparticle coating promotes their interaction with the corneal epithelial cells, improving the bioavailability of the ophthalmic pharmaceutical formulations. In fact, the physicochemical characteristics of the surface of the nanoparticles affect and determine the mucoadhesion properties of the nanoparticles on the eye tissues $(11,25,29,32,41,43,70,77)$. 
On the other hand, in order to develop successfully ophthalmic formulations prepared with lipid or polymeric nanoparticles it is necessary to disperse these systems in a suitable vehicle $(3,16,17,28,30)$. Thereby, the use of hydrogel formulations with nanoparticles has been described as possible semi-solid systems for topical, dermal and transdermal administration of drugs, since they increase the consistency of final formulations and also the long-term stability of the incorporated nanoparticles $(29,30,91,99-103)$. Therefore, if the semi-solid system is an in situ gelling system, this association may combine the properties of both classes of materials and may have a variety of biomedical applications $(29,38,39,91,104,105)$. In this way, both types of nanoparticles can be suspended, dispersed or entrapped in the hydrogel network, initiating an in situ gelling system, which has been characterized for gelling in contact with the eye tissues $(29,91)$. In situ gelling systems are made with specific polymers, namely stimuli-responsive polymers, which can undergo sol-gel transition when interacting with the ocular tissues (106-109).
Thereby, in the presence of these specific conditions present in the ocular globe (i.e., in the presence of specific $\mathrm{pH}$, temperature or certain electrolytes of the tear fluid), the polymeric pharmaceutical system turns, immediately and in a reversible way, into a gel, improving the precorneal retention, prolonging the corneal penetration, and increasing the therapeutic efficacy of the ophthalmic drugs $(16,17,33,35,36,110)$. The difference between these systems and the conventional hydrogels is the fact that the in situ gelling systems are dropped as a solution into the conjunctival sac, and undergo a transition into a gel induced by a change in the temperature, ion concentration or $\mathrm{pH}(3,4,111,112)$.

The stimuli-responsive polymers used in ophthalmic formulations can be categorized into three types: thermo-responsive polymers, $\mathrm{pH}$ responsive systems and ion-activated systems. Table 2 shows some examples of in situ activated gel-forming systems used in ophthalmic pharmaceutical formulations.

Table 2. Examples of in situ activated gel-forming systems used in ophthalmic pharmaceutical formulations.

\begin{tabular}{ccc}
\hline Thermo-responsive polymers & pH-responsive systems & Ion activated systems \\
\hline Poloxamers & Cellulose acetate hydrogen phthalate & Gellan gum $\left(\right.$ Gelrite $\left.^{\circledR}\right)$ \\
Cellulose derivatives & latex & Sodium alginate \\
Polymethacrylates & Chitosan & - \\
Poly $(N$-isopoprylacrilamide $)$ & Carbopols & - \\
(PNIPAAm) & Polycarbophil & - \\
Xyloglucan & - & \\
\hline
\end{tabular}

Therefore, it is fundamental to develop the correct composition and concentration of the hydrogel composed of a stimuli-responsive polymer(s), according to the physicochemical properties of the eye tissues, in order to create an in situ gelling system that undergoes the sol-gel transition immediately after eye instillation $(16,29,30,91)$. Usually this type of combination is prepared by adding the polymer(s) to the aqueous phase during nanoparticle preparation (2). However, some studies suggested that the preparation of nanoparticles and the in situ gelling system should be done separately and then mixed together, i.e., a weighed amount of nanoparticles was taken and dispersed in a certain amount of the in situ gelling polymer $(5,6,29,30,38,39,91)$. The mixture of nanoparticles and polymer is a crucial point for the preparation of ophthalmic semi-solid formulations. Therefore, it must be optimized in order to obtain the best results, namely concentration of the drug (amount of nanoparticles), concentration of the stimuliresponsive polymers, viscosity of the in situ gelling polymer after instillation, $\mathrm{pH}$ value, osmolarity and transparency of the formulation $(16,29,47,91)$.

The combination of nanoparticles and in situ gelling systems has already been used in several formulations administered by different routes, namely topical, dermal, transdermal and oral. As can be seen elsewhere in different studies, this combination has brought an added value to the 
pharmaceutical formulations, increasing the bioavailability and the therapeutic response $(91,99-103)$. More research in this area is needed, in order to consolidate the good results obtained in these studies, using different types of nanoparticles (polymeric and lipid) and other types of in situ gelling polymers. We believe that, due to the advantages of using this association of strategies, it is possible to improve the therapeutic activity of the incorporated drugs and obtain ophthalmic formulations that may rapidly pass to clinic.

\section{Critical aspects to consider in the development of ophthalmic formulations using a combination of nanoparticles and in situ gelling polymers}

Ophthalmic formulations are very specific and must comply with certain strict requirements. Generally, these types of formulations are similar to parenteral dosage forms in their requirement for sterility, as well as the considerations for osmotic pressure (isotonicity), preservation and tissue compatibility (47). Therefore, in order to develop ophthalmic formulations, based on in situ gelling systems and lipid nanoparticles (SLNs and NLCs), it is necessary to accomplish the following properties $(16,17)$ : isotonicity (to avoid eye irritation and lacrimation), viscosity (to avoid blurred vision), pseudoplastic and viscoelastic behaviour (to offer less resistance to blinking), mucoadhesiveness and wetting properties. Moreover, to develop and optimize a suitable ophthalmic pharmaceutical formulation it is necessary to give attention to the following critical points:

- Regular commercial eye drops range from 25 to $50 \mu \mathrm{l}$ in volume, because the estimated maximum volume of the cul-de-sac is about $30 \mu \mathrm{l}$, and the excess is rapidly removed through the lacrimal drainage system by the nasolacrimal duct to the nasal cavity $(7,9,47)$.

- The size of the carrier used in ophthalmic formulations should be as small as possible to facilitate corneal uptake, reach the inner tissues of the eye and promote mucoadhesion (55).

- The nanocarrier must be formulated in a suitable vehicle, preferably an in situ gelling system, which will increase the eye residence time of the drugs $(16,29,38,39)$.
- Non-Newtonian formulations that display pseudoplastic behaviour can undergo a viscosity decrease when the shear rate increases, favouring blinking and ocular movement (4). Formulations with pseudoplastic behaviour offer less resistance to blinking, making them better accepted than Newtonian formulations (4).

- The ophthalmic formulations before gelling should have a viscosity of 5 to $1000 \mathrm{mPa} . \mathrm{s}$, and after gelling in the ocular globe they should have a viscosity of about 50 to 50000 mPa.s (above this value there is blurred vision and a rapid elimination of the instilled formulation, due to an increase in reflex tears and reflex blinks) (113). When developing a formulation containing in situ gelling polymers, which undergo a sol-gel phase transition, it is fundamental to bear in mind that the gelation of the formulation occurs in the external ocular surface after the instillation of the ophthalmic formulation, despite its dilution in the tear fluid $(7,8)$.

- The $\mathrm{pH}$ values of the ophthalmic formulations should be as close as possible to the physiological fluids, in order to avoid irritation and lacrimation (extreme values between 5.0 and 8.5) (114).

- The positive charge surface of the carrier promotes the interaction of the colloidal systems with the polyanionic corneal and conjunctival surfaces, and thus improves the bioavailability of the ophthalmic formulations, increasing the drug retention and absorption $(11,29,32,41,43,70,77)$.

- In order to ensure the isotonicity, the osmolality of the ophthalmic formulations must be identical to the physiological fluids $(47,114,115)$.

\section{CONCLUSIONS}

The successful treatment of ocular pathologies depends upon the bioavailability of ophthalmic formulations. Therefore, there are many strategies to improve the bioavailability and the therapeutic response of drugs applied in the ocular globe. One of these most promising strategies is the use of colloidal carrier systems by means of lipid and polymeric nanoparticles. According to the different studies presented in this review, nanoparticles have been shown to be excellent carriers for enhancing the bioavailability of ophthalmic drugs because they present many advantages, namely excellent tolerability, 
biocompatibility and non-irritation sustained release, drug targeting and enhancement of the amount of drug penetrating into the ocular tissues. In the future, we believe that the development of polymeric and lipid nanoparticles dispersed in an in situ gelling system will be a successful strategy for improving the bioavailability of ophthalmic drugs, because this system extends their preocular retention and promotes their absorption. Nonetheless, despite the fact that the first studies that show this association for ophthalmic use have demonstrated very promising results, further research in this area is required.

\section{CONFLICT OF INTEREST}

The authors confirm that this article content has no conflicts of interest.

\section{ACKNOWLEDGEMENTS}

The authors would like to express their thanks to the Canadian Cancer Society for permission to use Figure 1 (Data: Figure 1. Structure of the eyeball; Property and Copyright: Canadian Cancer Society; Web page title: Anatomy and physiology of the eye; Web page address: http://www.cancer.ca/en/cancer-

information/cancer-type/eye/anatomy-andphysiology/?region=bc; Last accessed: 16 January 2014).

\section{LIST OF ABBREVIATIONS}

CS - Chitosan;

CO - Castor Oil;

COS - Chitosan Oligosaccharides;

CyA - Cyclosporine A;

Cys - Cysteine;

FP - Flurbiprofen;

HA - Hyaluronic acid;

HPH - High Pressure Homogenization;

NLC - Nanostructured Lipid Carrier;

PEG - Polyethylene glycol;

PLA - Polylactic acid;

PLGA - Poly(lactic-co-glycolic acid);

RCE - Rabbit corneal epithelial cells;

SA - Stearic Acid;

SLN - Solid Lipid Nanoparticles;

TA - Triamcinolone acetonide;

5-FU - 5-Fluorouracil;

\section{REFERENCES}

1. Diebold Y, Jarrin M, Saez V, Carvalho EL, Orea M, Calonge M, Seijo B, Alonso MJ. Ocular drug delivery by liposome-chitosan nanoparticle complexes (LCS-NP). Biomaterials, 2007; 28(8):1553-1564.

2. Araújo J, Gonzalez E, Egea MA, Garcia ML, Souto EB. Nanomedicines for ocular NSAIDs: safety on drug delivery. Nanomedicine, 2009; 5(4):394-401.

3. Ludwig A. The use of mucoadhesive polymers in ocular drug delivery. Adv Drug Deliv Rev, 2005; 57(11):1595-1639.

4. Achouri D, Alhanout K, Piccerelle P, Andrieu V. Recent advances in ocular drug delivery. Drug Dev Ind Pharm, 2013; 39(11):1599-1617.

5. Li J, Wu L, Wu W, Wang B, Wang Z, Xin H, Xu Q. A potential carrier based on liquid crystal nanoparticles for ophthalmic delivery of pilocarpine nitrate. Int J Pharm, 2013; 455(12):75-84.

6. Li X, Zhang Z, Chen H. Development and evaluation of fast forming nano-composite hydrogel for ocular delivery of diclofenac. Int $\mathrm{J}$ Pharm, 2013; 448(1):96-100.

7. Zimmer A, Kreuter J. Microspheres and nanoparticles used in ocular delivery systems. Adv Drug Deliv Rev, 1995; 16(1):61-73.

8. Zignani M, Tabatabay C, Gurny R. Topical semisolid drug delivery: kinetics and tolerance of ophthalmic hydrogels. Adv Drug Deliv Rev, 1995; 16(1):51-60.

9. Järvinen K, Järvinen T, Urtti A. Ocular absorption following topical delivery. Adv Drug Deliv Rev, 1995; 16(1):3-19.

10. Urtti A. Challenges and obstacles of ocular pharmacokinetics and drug delivery. Adv Drug Deliv Rev, 2006; 58(11):1131-1135.

11. Li X, Zhang Z, Wang M, Sun X, Nie S, Pan W. Liposome coated with low molecular weight chitosan and its potential use in ocular drug delivery. Int J Pharm, 2009; 379(1):131-138.

12. Araújo J, Veja E, Lopes C, Egea MA, Garcia ML, Souto EB. Effect of polymer viscosity on physicochemical properties and ocular tolerance of FB-loaded PLGA nanospheres. Colloids Surf B Biointerfaces, 2009; 72(1):48-56.

13. Bhattarai N, Gunn J, Zhang M. Chitosan-based hydrogels for controlled, localized drug delivery. Adv Drug Deliv Rev, 2010; 62(1):83-99.

14. Diebold Y, Calonge M. Applications of nanoparticles in ophthalmology. Prog Retin Eye Res, 2010; 29(6): 596-609.

15. Gan L, Wang J, Jiang M, Bartlett H, Ouyang D, Eperjesi F, Liu J, Gan Y. Recent advances in topical ophthalmic drug delivery with lipid-based nanocarriers. Drug Discov Today, 2013; 18(56):290-297.

16. Almeida H, Amaral MH, Lobão P, Sousa Lobo JM. Applications of poloxamers in ophthalmic pharmaceutical formulations: an overview. Expert Opin Drug Deliv, 2013; 10(9):1223-1237.

17. Almeida H, Amaral MH, Lobão P, Sousa Lobo JM. In situ gelling systems: a strategy to improve 
the bioavailability of ophthalmic pharmaceutical formulations. Drug Discov Today, 2014; 19(4):400-412.

18. Meisner D, Mezei M. Liposome ocular delivery systems. Adv Drug Deliv Rev, 1995; 16(1):75-93.

19. Pignatello R, Bucolo C, Spedalieri G, Maltese A, Puglisi G. Flurbiprofen-loaded acrylate polymer nanosuspensions for ophthalmic application. Biomaterials, 2002; 23(15):3247-3255.

20. Shen J, Deng Y, Jin X, Ping Q, Su Z, Li L. Thiolated nanostructured lipid carriers as a potential ocular delivery system for cyclosporine A: Improving in vivo ocular distribution. Int $\mathrm{J}$ Pharm, 2010; 402(1-2):248-253.

21. Gan L, Han S, Shen J, Zhu J, Zhu C, Zhang $X$, Gan Y. Self-assembled liquid crystalline nanoparticles as a novel ophthalmic delivery system for dexamethasone: Improving preocular retention and ocular bioavailability. Int J Pharm, 2010; 396(1-2): 179-187.

22. Müller RH, Shegokar R, Keck CM. 20 years of lipid nanoparticles (SLN and NLC): present state of development and industrial applications. Curr Drug Discov Technol, 2011; 8(3):207-227.

23. Moya-Ortega MD, Alves TFG, Alvarez-Lorenzo C, Concheiro A, Stefánsson E, Thorsteinsdóttir M, Loftsson T. Dexamethasone eye drops containing $\gamma$-cyclodextrin-based nanogels. Int $\mathrm{J}$ Pharm, 2013; 41(1-2):507-551.

24. Ribeiro A, Sandez-Macho I, Casas M, AlvarezPérez S, Alvarez-Lorenzo C, Concheiro A. Poloxamine micellar solubilization of $\alpha$ tocopherol for topical ocular treatment. Colloids Surf B Biointerfaces, 2013; 103(1):550-557.

25. Souto EB, Doktorovova S, Gonzalez-Mira E, Egea MA, Garcia ML. Feasibility of Lipid Nanoparticles for Ocular Delivery of Antiinflammatory Drugs. Curr Eye Res, 2010; 35(7):537-552.

26. Doktorovova S, Gokce E, Ozyazici M, Souto EB. Lipid Matrix Nanoparticles. Pharmacokinetics and Biopharmaceutics. Curr Nanosci, 2009; 5(3):358371.

27. De la Fuente, Raviña M, Paolicelli P, Sanchez A, Seijo B, Alonso MJ. Chitosan-based nanostructures: A delivery platform for ocular therapeutics. Adv Drug Deliv Rev, 2010; 62(1):100-117.

28. Pijls RT, Sonderkamp T, Daube GW, Krebber R,,Hanssen HH, Nuijts RM, Koole LH. Studies on a new device for drug delivery to the eye. Eur $\mathrm{J}$ Pharm Biopharm, 2005; 59(2):283-288.

29. Nagarwal RC, Kant S, Singh PN, Maiti P, Pandit JK. Polymeric nanoparticulate system: A potential approach for ocular drug delivery. J Control Release, 2009; 136(1): 2-13.

30. Silva AC, Amaral MH, González-Mira E, Santos D, Ferreira D. Solid lipid nanoparticles (SLN)based hydrogels as potential carriers for oral transmucosal delivery of Risperidone: Preparation and characterization studies. Colloids Surf B Biointerfaces, 2012; 93(1):241-248.

31. Hao J, Wang X, Bi Y, Teng Y, Wang J, Li F, Li Q, Zhang J, Guo F, Liu J. Fabrication of a composite system combining solid lipid nanoparticles and thermosensitive hydrogel for challenging ophthalmic drug delivery. Colloids Surf B Biointerfaces, 2014; 114:111-120.

32. Fresta M, Panico AM, Bucolo C, Giannavola C, Puglisi G. Characterization and in-vivo ocular absorption of liposome-encapsulated acyclovir. J Pharm Pharmacol, 1999; 51(5):565-567.

33. Bawa P, Pillay V, Choonara YE, Toit LC. Stimuliresponsive polymers and their applications in drug delivery. Biomed Mater, 2009; 4(2):1-15.

34. Nirmal HB, Bakliwal SR, Pawar SP. In-Situ gel: New trends in Controlled and Sustained Drug Delivery System. Int J Pharm Tech Res, 2010; 2(2): 1398-1408.

35. Rupenthal ID, Green CR, Alany RG. Comparison of ion-activated in situ gelling systems for ocular drug delivery. Part 1: Physicochemical characterisation and in vitro release. Int $\mathrm{J}$ Pharm, 2011; 411(1-2): 69-77.

36. El-Kamel AH. In vitro and in vivo evaluation of Pluronic F127-based ocular delivery system for timolol maleate. Int J Pharm, 2002; 241(1): 47-55.

37. Fangueiro JF, Andreani T, Egea MA, Garcia ML, Souto SB, Souto EB. Experimental factorial design applied to mucoadhesive lipid nanoparticles via multiple emulsion process. Colloids Surf B Biointerfaces, 2012; 100; 84-89.

38. Gupta H, Aqil M, Khar RK, Ali A, Bhatnagar A, Mittal G. Nanoparticles laden in situ gel of levofloxacin for enhanced ocular retention. Drug Deliv, 2013; 20(7):306-309.

39. Gupta H, Aqil M, Khar RK, Ali A, Bhatnagar A, Mittal G. Nanoparticles laden in situ gel for sustained ocular drug delivery. J Pharm Bioalled Sci, 2013; 5(2):162-165.

40. Finke JH, Schmolke H, Klages CP, MüllerGoymann CC. Controlling solid lipid nanoparticle adhesion by polyelectrolyte multilayer surface modifications. Int J Pharm, 2013; 449(1-2):59-71.

41. Shen J, Wang Y, Ping Q, Xiao Y, Huang X. Mucoadhesive effect of thiolated PEG stearate and its modified NLC for ocular drug delivery. J Control Release, 2009; 137(3):217-223.

42. Sinha VR, Singla AK, Wadhawan S, Kaushik R, Kumria R, Bansal K, Dhawan S. Chitosan microspheres as a potential carrier for drugs. Int $\mathrm{J}$ Pharm, 2004; 274(1-2):1-33.

43. Motwani SK, Chopra S, Talegaonkar S, Kohli K, Ahmad FJ, Khar RK. Chitosan-sodium alginate nanoparticles as submicroscopic reservoirs for ocular delivery: formulation, optimisation and in vitro characterisation. Eur J Pharm Biopharm, 2008; 68(3):513-525.

44. Yuan XB, Yuan YB, Jiang W, Liu J, Tian EJ, Shun HM, Huang DH, Yuan XY, Li H, Sheng J. Preparation of rapamycin-loaded chitosan/PLA 
nanoparticles for immunosuppression in corneal transplantation. Int J Pharm, 2008; 349(1-2):241248.

45. Mahmoud AA, El-Feky GS, Kamel R, Awad GEA. Chitosan/sulfobutylether- $\beta$-cyclodextrin nanoparticles as a potential approach for ocular drug delivery. Int J Pharm, 2011; 413(1-2):229236.

46. Bernkop-Schnürch A, Dünnhaupt S. Chitosanbased drug delivery systems. Eur J Pharm Biopharm, 2012; 81(3):463-469.

47. Troy, D.B.; Beringer, P., Remington: The science and Practice of Pharmacy. 21 $1^{\text {st }}$ ed., Lippincott Williams \& Wilkins, Philadelphia, USA, 2006.

48. Bourlais CL, Acar L, Zia H, Sado PA, Needham T, Leverge R. Ophthalmic drug delivery systems: recent advances. Prog Retin Eye Res, 1998; 17(1): 33-58.

49. Presland A, Myatt J. Ocular anatomy and physiology relevant to anaesthesia. Anaesth Intensive Care Medicine, 2010; 11(10):438-443.

50. Malhotra A, Minja FJ, Crum A, Burrowes D. Ocular Anatomy and Cross-Sectional Imaging of the Eye. Semin Ultrasound CT MRI, 2011; 32(1): 2-13.

51. Patil BB, Dowd TC. Physiological functions of the eye. Curr Anaesth Crit Care, 2000; 11(6): 293 298.

52. Rolando M, Zierhut M. The Ocular Surface and Tear Film and Their Dysfunction in Dry Eye Disease. Surv Ophthalmol, 2001; 45(2): S203S210.

53. Baeyens V, Percicot C, Zignani M, Gurny R, Kaltsatos VV, Deshpande AA. Ocular drug delivery in veterinary medicine. Adv Drug Deliv Rev, 1997; 28(3):335-361.

54. Müller-Goymann CC. Physicochemical characterization of colloidal drug delivery systems such as reverse micelles, vesicles, liquid crystals and nanoparticles for topical administration. Eur $\mathbf{J}$ Pharm Biopharm, 2004; 58(2):343-356.

55. Sahoo SK, Dilnawaz F, Krishnakumar S. Nanotechnology in ocular drug delivery. Drug Discov Today, 2008;13(3-4):144-151.

56. Silva AC, Santos D, Ferreira D, Lopes CM. Lipidbased Nanocarriers As An Alternative for Oral Delivery of Poorly Water- Soluble Drugs: Peroral and Mucosal Routes. Curr Med Chem, 2012; 19: 4495-510.

57. Gokce EH, Sandri G, Bonferoni MC, Rossi S, Ferrari F, Güneri T, Caramella C. Cyclosporine A loaded SLNs: Evaluation of cellular uptake and corneal cytotoxicity. Int J Pharm, 2008; 364(1):76-86.

58. Müller RH, Radtke M, Wissing SA. Solid lipid nanoparticles (SLN) and nanostructured lipid carriers (NLC) in cosmetic and dermatological preparations. Adv Drug Deliv Rev, 2002; 54 : S131-S155.

59. Souto EB, Müller RH. Investigation of the factors influencing the incorporation of clotrimazole in
SLN and NLC prepared by hot high-pressure homogenization. J Microencapsul, 2006; 23(4):377-388.

60. Araújo J, Gonzalez-Mira E, Egea MA, Garcia ML, Souto EB. Optimization and physicochemical characterization of a triamcinolone acetonideloaded NLC for ocular antiangiogenic applications. Int J Pharm, 2010; 393(1-2):167-175.

61. Luo Q, Zhao J, Zhang X, Pan W. Nanostructured lipid carrier (NLC) coated with Chitosan Oligosaccharides and its potential use in ocular drug delivery system. Int J Pharm, 2011; 403(12):185-191.

62. Gonzalez-Mira E, Egea MA, Garcia ML, Souto EB. Design and ocular tolerance of flurbiprofen loaded ultrasound-engineered NLC. Colloids Surf B Biointerfaces, 2010; 81(2):412-421.

63. Müller RH, Maassen S, Weyhers H, Mehnert W. Phagocytic uptake and cytotoxicity of solid lipid nanoparticles (SLN) sterically stabilized with poloxamine 908 and poloxamer 407. J Drug Target, 1996; 4(3):161-170.

64. Wake MC, Gerecht PD, Lu L, Mikos AG. Effects of biodegradable polymer particles on rat marrowderived stromal osteoblasts in vitro. Biomaterials, 1998; 19(14):1255-1268.

65. Ravi Kumar MNV, Nano and microparticles as controlled drug delivery devices. J Pharm Pharm Sci, 2000; 3(2):234-258.

66. Gupta H, Aqil M, Khar RK, Ali A, Bhatnagar A, Mittal G. Sparfloxacin-loaded PLGA nanoparticles for sustained ocular drug delivery. Nanomedicine, 2010; 6(2): 324:333.

67. Gupta H, Aqil M, Khar RK, Ali A, Bhatnagar A, Mittal G. Biodegradable levofloxacin nanoparticles for sustained ocular drug delivery. J Drug Target, 2011; 19(6):409-417.

68. Kumar R, Nagarwal RC, Dhanawat M, Pandit JK. In-vitro and in-vivo study of indomethacin loaded gelatin nanoparticles. J Biomed Nanotechnol, 2011; 7(3):325-333.

69. Nagarwal RC, Kumar R, Dhanawat M, Pandit JK. Modified PLA nano in situ gel: a potential ophthalmic drug delivery system. Colloids Surf B Biointerfaces, 2011; 86(1):28-34.

70. Nagarwal RC, Kumar R, Pandit JK. Chitosan coated sodium alginate-chitosan nanoparticles loaded with 5-FU for ocular delivery: in vitro characterization and in vivo study in rabbit eye. Eur J Pharm Sci, 2012; 47(4):678-685.

71. De Campos AM, Sanchez A, Alonso MJ. Chitosan nanoparticles: A new vehicle for the improvement of the delivery of drugs to the ocular surface. Application to cyclosporin A. Int J Pharm, 2001;224(1-2):159-168.

72. De Campos AM, Diebold Y, Carvalho EL, Sanchez A, Alonso MJ. Chitosan nanoparticles as new ocular drug delivery systems: In vitro stability, in vivo fate, and cellular toxicity. Pharm Res, 2004; 21(5):803-810. 
73. Giannavola C, Bucolo C, Maltese A, Paolino D, Vandelli MA, Puglisi G, Lee VH, Fresta M. Influence of preparation conditions on acyclovir loaded poly-d,l-lactic acid nanospheres and effect of PEG coating on ocular drug bioavailability. Pharm Res, 2003;20(4):584-590.

74. Kao HJ, Lin HR, Lo YL, Yu SP. Characterization of pilocarpine-loaded chitosan/carbopol nanoparticles. J Pharm Pharmacol, 2006; 58(2):179-186.

75. Agarwal KI, Mehta N, Namdev A. Gupta AK. InSitu Gel Formation for Ocular Drug Delivery System an Overview. Asia J Bio Pharm Sci, 2011; 1(4):01-07.

76. Ibrahim HK, El-Leithy IS, Makky AA. Mucoadhesive nanoparticles as carrier systems for prolonged ocular delivery of gatifloxacin/prednisolone bitherapy. Mol Pharm, 2010; 7(2):576-585.

77. Bhatta RS, Chandasana H, Chhonker YS, Rathi C, Kumar D, Mitra K, Shukla PK. Mucoadhesive nanoparticles for prolonged ocular delivery of natamycin: In vitro and pharmacokinetics studies. Int J Pharm, 2012; 432(1-2):105-112.

78. Müller RH, Mäder K, Gohla S. Solid lipid nanoparticles (SLN) for controlled drug delivery a review of the state of the art. Eur J Pharm Biopharm, 2000; 50(1):161-177.

79. Silva AC, González-Mira E, García ML, Egea MA, Fonseca J, Silva R, Santos D, Souto EB, Ferreira D. Preparation, characterization and biocompatibility studies on risperidone-loaded solid lipid nanoparticles (SLN): High pressure homogenization versus ultrasound. Colloids Surf B Biointerfaces, 2011; 86(1):158-165.

80. Silva AC, González-Mira E, Lobo JM, Amaral $\mathrm{MH}$. Current progresses on nanodelivery systems for the treatment of neuropsychiatric diseases: Alzheimer's and schizophrenia. Curr Pharm Des, 2013;19(41):7185-95.

81. Jenning V, Gysler A, Schafer-Korting M. Gohla SH. Vitamin A loaded solid lipid nanoparticles for topical use: occlusive properties and drug targeting to the upper skin. Eur J Pharm Biopharm, 2000; 49(3): 211-218.

82. Jenning V, Schafer-Korting M, Gohla S. Vitamin A-loaded solid lipid nanoparticles for topical use: active release properties. J Control Release, 2000; 66(2-3):115-126.

83. Ugazio E, Cavalli R, Gasco MR. Incorporation of cyclosporin A in solid lipid nanoparticles (SLN). Int J Pharm, 2002; 241(2):341-344.

84. Doktorovova S, Souto EB. Nanostructured lipid carrier-based hidrogel formulations for drug delivery: A comprehensive review. Expert Opin Drug Deliv, 2009; 6(2):165-175.

85. Kalam MA, Sultana Y, Ali A, Agil M, Mishra AK, Chuttani K. Preparation, characterization, and evaluation of gatifloxacin loaded solid lipid nanoparticles as colloidal ocular drug delivery system. J Drug Target, 2010; 18(3): 191-204.
86. Seyfoddin A, Al-Kassas R. Development of solid lipid nanoparticles and nanostructured lipid carriers for improving ocular delivery of acyclovir. Drug Dev Ind Pharm, 2012; 39(4):508-519.

87. Tian BC, Zhang WJ, Xu HM, Hao MX, Liu YB, Yang XG, Pan WS, Liu XH. Further investigation of nanostructured lipid carriers as an ocular delivery system: In vivo transcorneal mechanism and in vitro release study. Colloids Surf B Biointerfaces, 2013; 102(1):251-256.

88. Silva, A.C.; Santos, D.; Ferreira, D.; Souto, E.B., Advances in Nanoparticulate Carriers for Oral Peptides and Proteins: Polymeric vs. Lipid Nanoparticles. In: Encyclopedia of Nanoscience and Nanotechnology. American Scientific Publishers, Los Angeles, California, USA, pp 1$14,2010$.

89. Mehnert W, Mäder K. Solid lipid nanoparticles: production, characterization and applications. Adv Drug Deliv Rev, 2001;47(2-3):165-96.

90. Jores K, Mehnert W, Drechsler M, Bunjes H, Johann C, Mader K. Investigations on the structure of solid lipid nanoparticles (SLN) and oil-loaded solid lipid nanoparticles by photon correlation spectroscopy, field flow fractionation and transmission electron microscopy. J Control Release, 2004; 95(2): 217-227.

91. Souto EB, Doktorovova S. Chapter 6 - Solid Lipid Nanoparticle Formulations: Pharmacokinetic and Biopharmaceutical Aspects in Drug Delivery. Methods Enzymol, 2009; 464:105-129.

92. Huang ZR, Hua SC, Yang YL. Fang JY. Development and evaluation of lipid nanoparticles for camptothecin delivery: A comparison of solid lipid nanoparticles, nanostructured lipid carriers, and lipid emulsion. Acta Pharmacol Sin, 2008; 29(9): 1094-1102.

93. Olbrich C, Scholer N, Tabatt K, Kayser O, Müller RH. Cytotoxicity studies of Dynasan 114 solid lipid nanoparticles (SLN) on RAW 264.7 macrophages-impact of phagocytosis on viability and cytokine production. J Pharm Pharmacol, 2004; 56(7):883-891.

94. Cavalli R, Gasco MR, Chetoni P, Burgalassi S, Saettone MF. Solid lipid nanoparticles (SLN) as ocular delivery system for tobramycin. Int $\mathrm{J}$ Pharm, 2002; 238(1-2):241-245.

95. Attama AA, Reichl S, Müller-Goymann CC. Diclofenac sodium delivery to the eye: In vitro evaluation of novel solid lipid nanoparticle formulation using human cornea construct. Int $\mathrm{J}$ Pharm, 2008; 355(1-2):307-313.

96. Li X, Nie SF, Kong J, Li N, Ju CY, Pan W. A controlled-release ocular delivery system for ibuprofen based on nanostructured lipid carriers. Int J Pharm, 2008; 363(1-2):177-182.

97. Li R, Jiang S, Liu D, Bi X, Wang F, Zhang Q, Xu Q. A potential new therapeutic system for glaucoma: solid lipid nanoparticles containing methazolamide. J Microencapsul, 2011; 28(2):134-141. 
98. Liu Z, Zhang X, Wu H, Li J, Shu L, Liu R, Li L, Li N. Preparation and evaluation of solid lipid nanoparticles of baicalin for ocular drug delivery system in vitro and in vivo. Drug Dev Ind Pharm, 2011; 37(4):475-481.

99. Joshi M, Patravale V. Formulation and evaluation of Nanostructured lipid carrier (NLC)-based gel of Valdecoxib. Drug Dev Ind Pharm, 2006;32(8):911-918.

100.Casadei MA, Cerreto F, Cesa S, Giannuzzo M, Feeney M, Marianecci C, Paolicelli P. Solid lipid nanoparticles incorporated in dextran hydrogels: a new drug delivery system for oral formulations. Int J Pharm, 2006;325(1-2):140-146.

101.Joshi M, Patravale V. Nanostructured lipid carrier (NLC) based gel of celecoxib. Int J Pharm, 2008; 346(1-2):124-132.

102. Teeranachaideekul V, Souto EB, Muller RH, Junyaprasert VB. Physicochemical characterization and in vitro release studies of ascorbyl palmitate-loaded semi-solid nanostructured lipid carriers (NLC gels). J Microencapsul, 2008;25(2):111-120.

103. Bhaskar K, Krishna MC, Lingam M, Jagan Mohan S, Venkateswarlu V, Madhusudan Rao Y, Bhaskar K, Anbu J, Ravichandran V. Development of SLN and NLC enriched hydrogels for transdermal delivery of nitrendipine: in vitro and in vivo characteristics. Drug Dev Int Pharm, 2009;35(1):98-113.

104. Roy I, Gupta MN. Smart polymeric materials: Emerging biochemical applications. Chem Biol, 2003; 10(12):1161-1171.

105.Bajpai AK, Shukla SK, Bhanu S, Kankane S. Responsive polymers in controlled drug delivery. Prog Polym Sci, 2008; 33(11):1088-1118.

106.Jeong B, Gutowska A. Lessons from Nature: stimuli-responsive polymers and their biomedical applications. Trends Biotechnol, 2002; 20(7):305310.

107.Kumar A, Srivastata A, Galaev IY, Mattiasson B. Smart polymers: physical forms and bioengineering applications. Prog Polym Sci, 2007; 32(10):1205-1237.

108.Fogueri LR, Singh S. Smart polymers for controlled delivery of proteins and peptides: A review of patents. Recent Pat Drug Deliv Formul, 2009; 3(1):40-48.

109. Shaikh RP, Pillay V, Choonara YE, Toit LC, Ndesendo VMK, Bawa P, Cooppan S. A review of multi-responsive membranous systems for rate-modulated drug delivery. AAPS Pharmscitech, 2010; 2(1):441-459.

110.Sandri G, Bonferoni MC, Rossi S, Ferrari F, Mori M, Del Fante C, Perotti C, Caramella C. Thermosensitive eyedrops containing platelet lysate for the treatment of corneal ulcers. Int J Pharm, 2012; 426(1-2):1-6.

111.Kopecek J. Hydrogel biomaterials: A smart future? Biomaterials 2007; 28(34):5185-5192.

112.Kim S, Kim JH, Jeon O, Kwon IC, Park K. Engineered polymers for advanced drug delivery. Eur J Pharm Biopharm, 2009; 71(3):420-430.

113. Mohanambal E, Arun k, Abdul Hasan Sathali A. Formulation and Evaluation of $\mathrm{pH}$-triggered in situ Gelling System of Levofloxacin. Indian J Pharm Educ Res, 2011; 45(1): 58-64.

114.Prista, L.N.; Alves, A.C.; Morgado, R.; Sousa Lobo, J.M., Tecnologia Farmacêutica. $6^{\text {st }}$ ed., Fundação Calouste Gulbenkian, Lisbon, Portugal, 2002.

115.Sinko, P.J., Martin's Physical Pharmacy and Pharmaceutical Sciences. $6^{\text {th }}$ ed., Lippincott Williams \& Wilkins, Philadelphia, USA, 2011. 